\title{
Correction to: Salient object detection using the phase information and object model
}

\section{Hooman Afsharirad ${ }^{1} \cdot$ Seyed Alireza Seyedin ${ }^{2}$}

Published online: 11 March 2019

(C) Springer Science+Business Media, LLC, part of Springer Nature 2019

\section{Correction to: Multimedia Tools and Application. https://doi.org/10.1007/s11042-019-7255-7}

The article Salient object detection using the phase information and object model, written by Hooman Afsharirad and Seyed Alireza Seyedin, was originally published electronically on the publisher's internet portal (currently SpringerLink) on February 7, 2019 with open access.

With the author(s)' decision to step back from Open Choice, the copyright of the article changed on March 2019 to $@$ Springer Science+Business Media, LLC, part of Springer Nature 2019 and the article is forthwith distributed under the terms of copyright.

The original article has been corrected.

Publisher's note Springer Nature remains neutral with regard to jurisdictional claims in published maps and institutional affiliations.

The online version of the original article can be found at https://doi.org/10.1007/s11042-019-7255-7

Hooman Afsharirad

hooman.afsharirad@khorasan.ac.ir

1 Khorasan Institute of Higher Education, Moalem 77, Mashhad, Iran

2 Faculty of Engineering, Ferdowsi University of Mashhad, Azadi square, Mashhad, Iran 